\title{
Article \\ Sex Differences in Circadian Clock Genes and Myocardial Infarction Susceptibility
}

\author{
Ivana Škrlec ${ }^{1, *}$, Jasminka Talapko ${ }^{1}\left(\right.$,, Martina Juzbašić ${ }^{1}$ and Robert Steiner ${ }^{2,3}$ \\ 1 Faculty of Dental Medicine and Health, Josip Juraj Strossmayer University of Osijek, HR-31000 Osijek, Croatia; \\ jtalapko@fdmz.hr (J.T.); mjuzbasic@fdmz.hr (M.J.) \\ 2 Faculty of Medicine, Josip Juraj Strossmayer University of Osijek, Josipa Huttlera 4, HR-31000 Osijek, Croatia; \\ steiner_robert5@hotmail.com \\ 3 Clinical Department of Cardiovascular Diseases and Intensive Care, Clinic for Internal Medicine, University \\ Hospital Osijek, Josipa Huttlera 4, HR-31000 Osijek, Croatia \\ * Correspondence: iskrlec@fdmz.hr
}

Citation: Škrlec, I.; Talapko, J.; Juzbašić, M.; Steiner, R. Sex Differences in Circadian Clock Genes and Myocardial Infarction Susceptibility. J. Cardiovasc. Dev. Dis. 2021, 8, 53. https://doi.org/10.3390/ jcdd 8050053

Academic Editor: Andy Wessels

Received: 24 February 2021

Accepted: 7 May 2021

Published: 8 May 2021

Publisher's Note: MDPI stays neutral with regard to jurisdictional claims in published maps and institutional affiliations.

Copyright: () 2021 by the authors. Licensee MDPI, Basel, Switzerland. This article is an open access article distributed under the terms and conditions of the Creative Commons Attribution (CC BY) license (https:// creativecommons.org/licenses/by/ $4.0 /)$

\begin{abstract}
The growing body of evidence shows a significant difference in the circadian rhythm of cardiovascular disease based on biological sex. The incidence of cardiovascular disease varies between women and men. Additionally, biological sex is vital for the timely application of therapychronotherapy, which benefits both sexes. This study aimed to examine the potential difference of single nucleotide polymorphisms (SNPs) of the circadian rhythm genes ARNTL, CLOCK, CRY2 and PER2 in women and men with myocardial infarction. A cross-sectional study was conducted, including 200 patients with myocardial infarction. Altogether, ten single nucleotide polymorphisms in the ARNTL, CLOCK, CRY2 and PER2 genes were analyzed. The Chi-square test yielded statistically significant differences in CLOCK gene rs11932595 polymorphism in a recessive genotype model between women and men with a p-value of 0.03 and an odds ratio 2.66, and a corresponding $95 \%$ confidence interval of 1.07 to 6.66. Other analyzed polymorphisms of the circadian rhythm genes ARNTL, CRY2, and PER2 did not significantly differ between the sexes. According to the study's current results, the CLOCK gene's genetic variability might affect myocardial infarction concerning biological sex.
\end{abstract}

Keywords: biological sex; circadian rhythm; clock genes; myocardial infarction

\section{Introduction}

Circadian rhythm affects daily the physiological functioning that is important for the proper functioning of peripheral organs, including the heart [1]. The central molecular clock is located in the suprachiasmatic nucleus (SCN) and controls peripheral molecular clocks located in almost all organs [2]. Thus, circadian rhythms are essential for normal physiology, and if there is a desynchronization between the central and peripheral clocks, disease develops [3,4]. The molecular clock's basis consists of a transcriptional and translational feedback loop of four key transcription factors. CLOCK and ARNTL (BMAL1) heterodimers form a positive loop that stimulates PER and CRY transcription and other clock-linked genes. A negative feedback loop is composed of PER and CRY heterodimers, which inhibits the transcription of CLOCK and ARNTL genes [5,6].

Circadian rhythm influences daily body functions such as temperature, hormone release, digestion, sleep, and mood [7,8]. Many cardiovascular functions are also regulated by circadian rhythms, such as blood pressure, heart rate, endothelial function, and thrombus formation [3,9-12]. Circadian rhythm disorders can have negative consequences for the whole organism, including the cardiovascular system, which leads to an increased risk of heart disease $[13,14]$.

Numerous studies have shown a significant difference in circadian rhythm on cardiovascular disease (CVD) based on sex [3]. It has been shown that women are somewhat 
more sensitive to circadian rhythm disorders and have an increased risk of chronic diseases affecting the reproductive and immune systems, central nervous system, endocrine functions, and cardiovascular health $[7,8]$. Many physiological processes that are regulated by circadian rhythms differ between women and men. Therefore, women have higher systolic and diastolic blood pressure at night than men [15]. Women have a higher heart rate [16], are more sensitive to sleep disorders than men [8], and have been shown to have a shorter circadian period than men [17]. Many CVDs are associated with obesity, the onset of which is mainly sex-related [18]. Sex plays a vital role in the circadian disorder of energy homeostasis [19]. Women are more sensitive to insulin and have higher adiponectin and leptin levels, while men have higher triglycerides levels in the blood [18-20]. Circadian disorder in women stimulates adipose tissue storage, while fat stores' mobilization is more effective in men [18]. Men are less susceptible to circadian rhythm disorders [19]. Different triggers could affect the various incidence of CVD between men and women. These triggers may be due to exposure to multiple factors, sex-specific cardiac mechanisms, or both [21].

The circadian rhythm influences heart disease in a sexually dimorphic manner [9]. Women and men differ in their resistance to cardiovascular disease, with sex hormones and sex chromosomes playing an important role [3,9,18,22-24]. Studies in rodents have shown that female mice have a higher survival rate after myocardial infarction (MI) than male mice [25]. Additionally, despite disturbed circadian rhythm, female mice are protected from the development of metabolic changes and cardiomyopathy [13]. Sex hormones, estrogens, are thought to play a protective role against CVD development, including MI. Estrogens influence circadian molecular clock gene expression, which is essential in regulating circadian rhythm via SCN [22]. Premenopausal women have less CVD than men of the same age, but that changes when women reach menopause. Then, estrogen's cardioprotective effect is lost, and elevated testosterone levels lead to hypertension and coronary artery disease in postmenopausal women [24,26]. Cardiolipin composition was observed to differ in female and male mice's heart cells, which may affect MI resistance in females [9]. Cardiolipins are an essential part of mitochondria's inner membrane and play a crucial role in mitochondria's bioenergetics, and their composition is altered in heart disease [13]. Another possible explanation for the lower incidence of CVD in women is that women may have unrecognized CVD symptoms, including myocardial infarction, and are less likely to report chest pain associated with acute coronary syndrome [27]. Additionally, it is known that a large number of women with acute MI die before hospitalization [27]. Studies have shown a significant reduction in morbidity and mortality from atherosclerosis in men, while the rate of recurrent atherothrombotic events, including cardiovascular death, has increased in women [28]. The mechanisms of circadian rhythm act differently in the hearts of women compared to men. Women and men show flexibility in cardiovascular disease, and biological sex is crucial for circadian therapy to benefit both sexes [9].

All of the mentioned above led to this study's aim to investigate the potential difference in ARNTL, CLOCK, CRY2, and PER2 circadian rhythm gene polymorphisms in women and men with myocardial infarction.

\section{Participants and Methods}

\subsection{Participants}

A cross-sectional study was conducted, including 200 patients with myocardial infarction. Of these, 86 were women, and 114 were men. Subjects were patients with a history of myocardial infarction hospitalized at the University Hospital Osijek, Croatia. Patients with type I and II myocardial infarction with elevated cardiac troponin $\mathrm{T}$ above the 99th percentile were included in the study and with one of the subsequent factors: electrocardiogram (ECG) changes, pathological $Q$ waves, myocardial ischemia symptoms, loss of viable myocardium or regional wall motion abnormalities, or coronary thrombus identified by angiography $[29,30]$. Patients were excluded from this study if they had undergone percutaneous coronary intervention $(n=35)$ or a coronary artery bypass $(n=42)$ because those are not clinical characteristics of acute MI. Additionally, patients were excluded if 
they had cancer ( $n=48)$, cardiomyopathy $(n=21)$, or other circadian rhythm-regulated diseases, such as sleep disorders $(n=94)$ and mood disorders $(n=68)$, including depression (Figure 1).

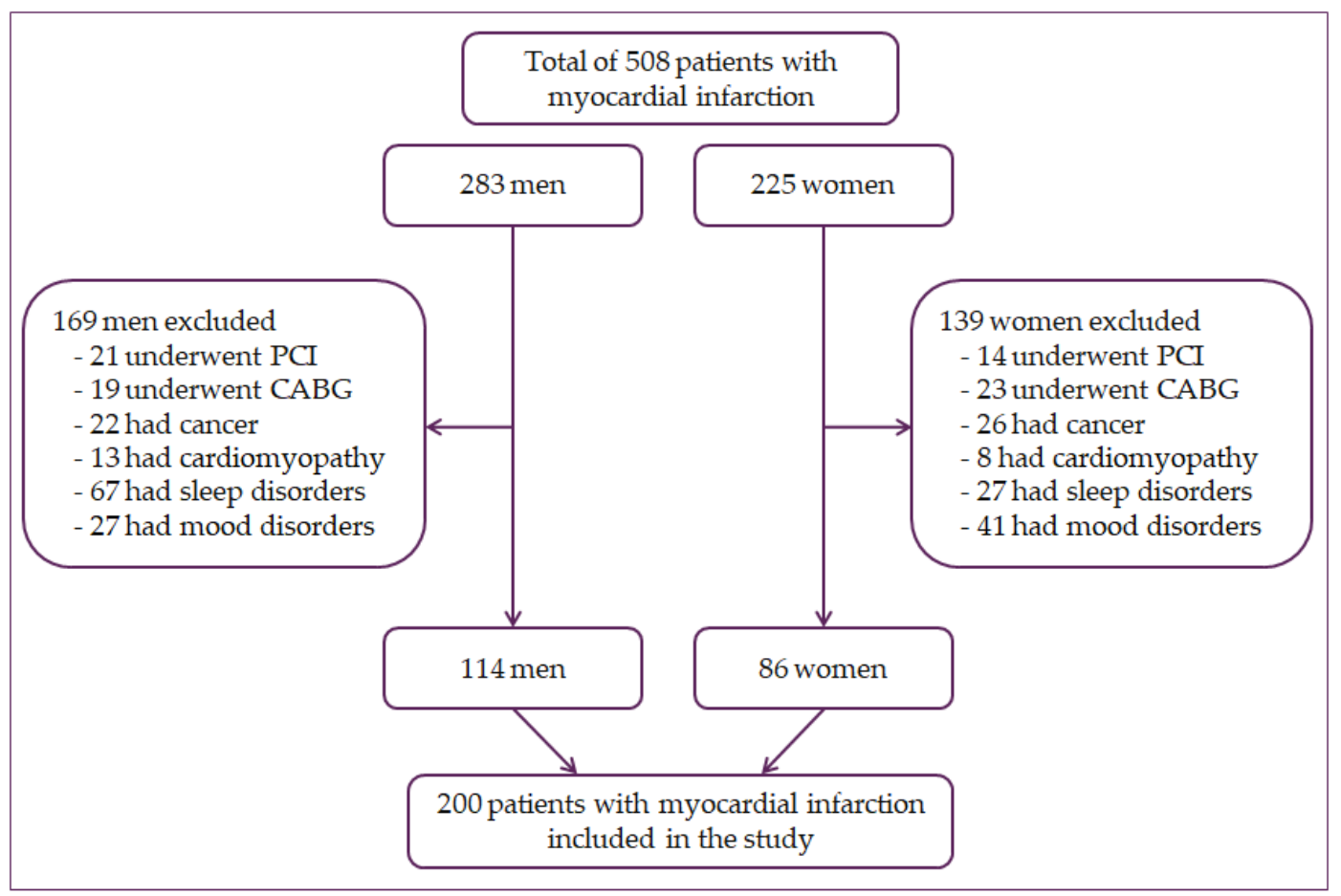

Figure 1. Flowchart of patient selection. PCI—percutaneous coronary intervention, CABG—coronary artery bypass grafting.

Data on the patient's medical history and sociodemographic data were collected. All data were additionally checked in the patient's medical records.

The Ethics Committee of the University Hospital Osijek (Ethical Approval Code: 25-1: 3160-3/2012) approved this research. According to the Declaration of Helsinki and its amendments, the study was carried out. All participants signed informed consent forms.

\subsection{Genotyping of Single Nucleotide Polymorphisms}

In this study, SNPs were determined in four circadian rhythm genes: CLOCK, ARNTL, CRY2, and PER2. A total of ten SNPs were analyzed. Three SNPs in the ARNTL gene (rs3789327, rs4757144 and rs12363415), and CLOCK (rs11932595, rs6811520 and rs13124436). Meanwhile, two SNPs were analyzed in the CRY2 (rs2292912 and rs10838524) and PER2 genes (rs35333999 and rs934945). These central clock gene polymorphisms have been associated with cardiovascular risk factors in earlier research [14,31-33]. All tested polymorphisms are located in the intronic region of the genes, except for PER2 gene polymorphisms.

According to the manufacturer's standard protocol, the extraction of genomic DNA was made from peripheral blood lymphocytes (QIAamp DNA Blood Mini Kit, Qiagen, Hilden, Germany). All analyses were conducted by real-time PCR using TaqMan probes. Allele discrimination analyses were performed with SDS 7500 software version 2.3 (Applied Biosystems, Foster City, CA, USA).

\subsection{Statistical Analyses}

Statistical analyses were carried out with SPSS software (version 22.0, SPSS Inc., Chicago, IL, USA) for Windows. Quantitative data are shown as the mean and standard deviation, while categorical data are shown as frequency and percentages. For each SNP, a significant difference was calculated to compare allele frequency and genotype distribution in women and men using the Chi-Square test $(\chi 2)$ on contingency tables. An additional 
level of genotyping quality control was achieved by applying the Chi-square goodness-offit test and analyzing genotypes' distribution with those expected in the Hardy-Weinberg equilibrium. Genotype models were determined using the web tool SNPStats [34]. Logistic regression was used to estimate the effect of ARNTL (rs3789327, rs4757144, rs12363415), CLOCK (rs11932595, rs6811520, rs13124436), CRY2 (rs2292912 and rs10838524) and PER2 (rs35333999 and rs934945) genotypes on the patients' sex. Age, smoking, history of hypertension, dyslipidemia, type 2 diabetes mellitus, positive family history of CVD, history of former CVD, systolic and diastolic blood pressure, and BMI were used as a covariate. Kruskal-Wallis and Chi-square tests were utilized to define the association of cardiovascular risk factors with polymorphisms of the analyzed molecular clock genes. In the case where $p \leq 0.05$, the association was considered significant. Significant value corrections were made by the Benjamini-Hochberg method (false detection rate-FDR value) due to several polymorphisms tested. Only q-values less than 0.05 were considered significant. The most common haplotypes and the association between haplotypes and CVD risk factors were identified by the SNPStats web tool [34]. Only an additive model was considered due to the low frequency of some haplotypes.

\section{Results}

Demographic and clinical characteristics of women and men are presented in Table 1. The mean age of all participants was $66 \pm 12$ years, and $57 \%$ were men.

Table 1. Demographic and clinical characteristics of patients.

\begin{tabular}{cccc}
\hline Variable & Women & Men & $p$-Value \\
\hline Number (\%) & $86(43 \%)$ & $114(57 \%)$ & - \\
Age (years) & $69 \pm 12$ & $64 \pm 12$ & $\mathbf{0 . 0 0 2} *$ \\
Smoking & $16(18.6 \%)$ & $25(21.9 \%)$ & $<\mathbf{0 . 0 0 1}+$ \\
Hypertension & $50(58.1 \%)$ & $57(50 \%)$ & $0.25+$ \\
Dyslipidemia & $17(19.8 \%)$ & $9(7.9)$ & $\mathbf{0 . 0 1 3}+$ \\
Type 2 diabetes mellitus & $18(20.9 \%)$ & $26(22.8 \%)$ & $0.75+$ \\
Positive family history of CVD & $29(25.4 \%)$ & $18(20.9 \%)$ & $0.18+$ \\
History of former CVD & $82(71.9 \%)$ & $61(70.9 \%)$ & $0.33+$ \\
Systolic blood pressure (mm Hg) & $127.55 \pm 18.21$ & $126.14 \pm 13.89$ & 0.97 \\
Diastolic blood pressure (mm Hg) & $75.77 \pm 10.86$ & $77.27 \pm 9.25$ & 0.46 \\
BMI (kg/m $\left.{ }^{2}\right)$ & $29.31 \pm 4.19$ & $28.30 \pm 5.07$ & 0.09 \\
\hline
\end{tabular}

* Mann-Whitney U test, + Chi-squared test, BMI—body mass index. The bold are statistically significant values.

After Bonferroni correction, a significant difference was found in the recessive genotype model of CLOCK rs11932595 polymorphism (GG vs. AG + AA) in women compared to men ( $p=0.03$, the odds ratio of $2.66,95 \%$ confidence interval 1.07 to 6.66$)$. Other genotype models of $A R N T L, C R Y 2$ and PER2 genes were not significantly different between women and men (Table 2).

Logistic regression was adjusted to evaluate the independent impact of the chosen polymorphism after modifying for age and cardiovascular risk factors. All tested SNPs showed a significant interaction between age $(p=0.017)$, smoking $(p<0.001)$, and diastolic blood pressure $(p=0.045)$ (Table 3).

The chi-square test compared the allelic frequency and genotype distribution between women and men (Table 4). Women and men were not significantly different in tested polymorphisms or genotype distribution in ARNTL, CLOCK, CRY2, or PER2 genes.

The association was found among cardiovascular risk factors and examined circadian rhythm gene polymorphisms in women and men (Table 5). The SNP rs12363415 in the ARNTL gene was associated with type 2 diabetes mellitus in women $(p=0.003)$. In contrast, rs2292912 in the CRY2 gene and rs934945 in the PER2 gene were associated with dyslipidemia in the men ( $p=0.02$, and $<0.001$, respectively). The CLOCK polymorphism rs11932595 was associated with systolic and diastolic blood pressure in women ( $p=0.005$ and $p=0.006$, respectively) and BMI in men $(p=0.024)$. 
The haplotypes were examined in the four circadian clock genes. The frequencies of the predicted haplotypes of the tested circadian clock gene polymorphisms in women and men are shown in the supplementary material (Supplemental Table S1). The haplotype CGA distribution at the ARNTL gene locus was statistically significantly different when comparing haplotype frequency between women and men $(p=0.030, \mathrm{OR}=1.86,95 \% \mathrm{CI}$ $=1.05-3.27)$. The CGA haplotype of the ARNTL gene was significantly associated with dyslipidemia and hypertension under the additive model $(p=0.03, \mathrm{OR}=0.45,95 \% \mathrm{CI}$ $=0.22-0.95$, and $p=0.03, \mathrm{OR}=0.29,95 \% \mathrm{CI}=0.09-0.88$, respectively). Furthermore, a significant difference was observed at the $C R Y 2$ gene locus when comparing the haplotype GG frequency between women and men $(p<0.001$, OR $=9.73,95 \% \mathrm{CI}=9.71-9.76)$. The CA and GA haplotypes of the $C R Y 2$ gene were significantly associated with dyslipidemia under the additive model $(p=0.02, \mathrm{OR}=8.20,95 \% \mathrm{CI}=1.42-47.45$, and $p=0.03, \mathrm{OR}=6.44$, $95 \% \mathrm{CI}=1.09-37.89$, respectively).

Table 2. Genotype models of the ARNTL, CLOCK, CRY2, and PER2 polymorphisms.

\begin{tabular}{|c|c|c|c|c|c|c|c|c|c|}
\hline \multirow[t]{2}{*}{ Gene } & \multicolumn{3}{|c|}{ Codominant Model } & \multicolumn{3}{|c|}{ Dominant Model } & \multicolumn{3}{|c|}{ Recessive Model } \\
\hline & $p$ & OR & $95 \%$ CI & $p$ & OR & $95 \%$ CI & $p$ & OR & $95 \%$ CI \\
\hline \multicolumn{10}{|c|}{ ARNTL } \\
\hline rs3789327 & 0.18 & 0.56 & $0.29-1.07$ & 0.06 & 0.56 & $0.30-1.04$ & 0.56 & 0.80 & $0.37-1.70$ \\
\hline rs4757144 & 0.48 & 1.28 & $0.69-2.39$ & 0.67 & 1.13 & $0.63-2.02$ & 0.36 & 0.69 & $0.31-1.52$ \\
\hline rs12363415 & 0.77 & 1.05 & $0.56-1.99$ & 0.98 & 1.01 & $0.54-1.88$ & 0.48 & 0.43 & $0.04-4.89$ \\
\hline \multicolumn{10}{|c|}{ CLOCK } \\
\hline rs11932595 & 0.08 & 0.93 & $0.50-1.72$ & 0.67 & 1.14 & $0.63-2.05$ & 0.03 & 2.66 & $1.07-6.66$ \\
\hline rs6811520 & 0.45 & 0.78 & $0.42-1.46$ & 0.28 & 0.72 & $0.40-1.31$ & 0.33 & 0.68 & $0.31-1.47$ \\
\hline rs13124436 & 0.95 & 0.97 & $0.53-1.77$ & 0.99 & 1.00 & $0.57-1.77$ & 0.76 & 1.15 & $0.46-2.87$ \\
\hline \multicolumn{10}{|c|}{ CRY2 } \\
\hline rs2292912 & 0.99 & 0.97 & $0.54-1.76$ & 0.94 & 0.98 & $0.55-1.75$ & 0.96 & 1.05 & $0.17-6.60$ \\
\hline rs10838524 & 0.30 & 1.46 & $0.75-1.97$ & 0.46 & 1.26 & $0.68-2.36$ & 0.28 & 0.67 & $0.33-1.38$ \\
\hline \multicolumn{10}{|c|}{ PER2 } \\
\hline rs35333999 & 0.89 & 1.24 & $0.42-3.72$ & 0.79 & 1.15 & $0.41-3.21$ & 0.77 & 0.66 & $0.04-10.76$ \\
\hline rs934945 & 0.43 & 1.23 & $0.64-2.34$ & 0.79 & 1.09 & $0.59-2.01$ & 0.25 & 0.39 & $0.07-2.11$ \\
\hline
\end{tabular}

$p$-Values shown in the table are corrected for the multiple comparisons. The bold is statistically significant value.

Table 3. Odds ratios for the difference between sex, adjusted for age, and cardiovascular risk factors included in the logistic regression model.

\begin{tabular}{ccc}
\hline Risk Factor & OR (95\% CI) & $p$ Value \\
\hline Age & $0.96(0.94-0.99)$ & $\mathbf{0 . 0 1 7}$ \\
Smoking & $2.24(1.45-3.47)$ & $<\mathbf{0 . 0 0 1}$ \\
Hypertension & $1.06(0.53-1.44)$ & 0.86 \\
Dyslipidemia & $2.36(0.85-6.56)$ & 0.10 \\
Type 2 diabetes mellitus & $0.85(0.37-1.95)$ & 0.71 \\
Positive family history of CVD & $1.20(0.69-2.09)$ & 0.51 \\
History of former CVD & $0.92(0.59-1.44)$ & 0.72 \\
Systolic blood pressure (mm Hg) & $0.97(0.94-1.00)$ & 0.07 \\
Diastolic blood pressure (mm Hg) & $1.05(1.01-1.11)$ & $\mathbf{0 . 0 4 5}$ \\
BMI $\left(\mathrm{kg} / \mathrm{m}^{2}\right)$ & $0.96(0.89-1.03)$ & 0.27 \\
\hline
\end{tabular}

BMI—body mass index. The bold are statistically significant values. 
Table 4. Allele and genotype distribution and frequencies of the ARNTL, CLOCK, CRY2, and PER2 polymorphisms.

\begin{tabular}{|c|c|c|c|c|c|c|c|c|c|c|c|c|}
\hline \multirow{2}{*}{ Gene } & \multirow{2}{*}{ SNP } & \multirow{2}{*}{ Minor Allele } & \multirow{2}{*}{ MAF * Women } & \multirow{2}{*}{ MAF* Men } & \multirow{2}{*}{$p$-Value } & \multirow{2}{*}{$q$ Value } & \multirow{2}{*}{ Genotype } & \multicolumn{5}{|c|}{ Genotype Frequency, $\mathbf{N}(\%)$} \\
\hline & & & & & & & & Women & Men & $p$ Value & $x^{2}$ & $q$ Value \\
\hline \multirow{9}{*}{ ARNTL } & \multirow{3}{*}{ rs3789327 } & \multirow{3}{*}{ c } & \multirow{3}{*}{0.46} & \multirow{3}{*}{0.38} & \multirow{3}{*}{0.118} & \multirow{3}{*}{0.125} & TT & $23(26.7 \%)$ & $44(38.5 \%)$ & \multirow{3}{*}{0.210} & \multirow{3}{*}{3.11} & \multirow{3}{*}{0.216} \\
\hline & & & & & & & TC & $47(54.6 \%)$ & $53(46.4 \%)$ & & & \\
\hline & & & & & & & $\mathrm{CC}$ & $16(18.6 \%)$ & $17(14.9 \%)$ & & & \\
\hline & \multirow{3}{*}{ rs4757144 } & \multirow{3}{*}{ G } & \multirow{3}{*}{0.38} & \multirow{3}{*}{0.37} & \multirow{3}{*}{0.823} & \multirow{3}{*}{0.835} & AA & $35(40.6 \%)$ & $44(38.5 \%)$ & \multirow{3}{*}{0.578} & \multirow{3}{*}{1.09} & \\
\hline & & & & & & & $\mathrm{AG}$ & $36(41.8 \%)$ & $55(48.2 \%)$ & & & 0.577 \\
\hline & & & & & & & GG & $15(17.4 \%)$ & $15(13.1 \%)$ & & & \\
\hline & & & & & & & AA & $61(70.9 \%)$ & $81(71 \%)$ & & & \\
\hline & rs12363415 & G & 0.16 & 0.15 & 0.828 & 0.888 & AG & $23(26.7 \%)$ & $32(28 \%)$ & 0.698 & 0.72 & 0.757 \\
\hline & & & & & & & GG & $2(2.3 \%)$ & $1(0.8 \%)$ & & & \\
\hline & & & & & & & $\mathrm{AA}$ & $32(37.2 \%)$ & $41(35.9 \%)$ & & & \\
\hline & rs11932595 & G & 0.35 & 0.41 & 0.214 & 0.255 & AG & $47(54.6 \%)$ & $52(45.6 \%)$ & 0.103 & 4.53 & 0.102 \\
\hline & & & & & & & GG & $7(8.1 \%)$ & $21(18.4 \%)$ & & & \\
\hline & & & & & & & $\mathrm{CC}$ & $29(33.7 \%)$ & $46(40.3 \%)$ & & & \\
\hline CLOCK & rs6811520 & $\mathrm{T}$ & 0.42 & 0.36 & 0.220 & 0.254 & СT & $41(47.6 \%)$ & $53(46.4 \%)$ & 0.465 & 1.53 & 0.486 \\
\hline & & & & & & & TT & $16(18.6 \%)$ & $15(13.1 \%)$ & & & \\
\hline & & & & & & & $\mathrm{AA}$ & $9(10.4 \%)$ & $13(11.4 \%)$ & & & \\
\hline & rs13124436 & A & 0.32 & 0.33 & 0.846 & 0.914 & AG & $37(43 \%)$ & $49(42.9 \%)$ & 0.976 & 0.05 & 1 \\
\hline & & & & & & & GG & $40(46.5 \%)$ & $52(45.6 \%)$ & & & \\
\hline & rs2292912 & G & 0.20 & 0.20 & 1 & 1 & CG & $31(36 \%)$ & $40(35 \%)$ & 0.982 & 0.03 & 0.999 \\
\hline P & & & & & & & GG & $2(2.3 \%)$ & $3(2.6 \%)$ & & & \\
\hline NATL & & & & & & & GG & $27(31.3 \%)$ & $30(26.3 \%)$ & & & \\
\hline & rs10838524 & A & 0.45 & 0.45 & 1 & 1 & GA & $40(46.5 \%)$ & $65(57 \%)$ & 0.327 & 2.23 & 0.317 \\
\hline & & & & & & & AA & $19(22 \%)$ & $19(16.6 \%)$ & & & \\
\hline & & & & & & & $\mathrm{CC}$ & $79(91.8 \%)$ & $104(91.2 \%)$ & & & \\
\hline & rs353333999 & $\mathrm{T}$ & 0.05 & 0.05 & 1 & 1 & СT & $6(6.9 \%)$ & $9(7.8 \%)$ & 0.952 & 0.09 & 0.999 \\
\hline רקחק & & & & & & & TT & $1(1.1 \%)$ & $1(0.8 \%)$ & & & \\
\hline$P E R 2$ & & & & & & & CC & $60(69.7 \%)$ & $78(68.4 \%)$ & & & \\
\hline & rs934945 & $\mathrm{T}$ & 0.18 & 0.16 & 0.722 & 0.789 & СT & $21(24.4 \%)$ & $34(29.8 \%)$ & 0.241 & 2.84 & 0.247 \\
\hline & & & & & & & $\begin{array}{l}\text { TT } \\
\end{array}$ & $5(5.8 \%)$ & $2(1.7 \%)$ & & & \\
\hline
\end{tabular}

${ }^{*}$ MAF—minor allele frequency, $q$ value—corrected significant $p$-value by the Benjamini-Hochberg method. 
Table 5. The association between cardiovascular risk factors and circadian clock gene SNPs.

\begin{tabular}{|c|c|c|c|c|c|c|c|c|c|c|c|c|c|c|c|c|c|c|c|c|}
\hline \multirow[t]{2}{*}{ Gene } & \multicolumn{2}{|c|}{ Age * } & \multicolumn{2}{|c|}{ Smoking +} & \multicolumn{2}{|c|}{ Hypertension $\dagger$} & \multicolumn{2}{|c|}{ Dyslipidemia ${ }^{+}$} & \multicolumn{2}{|c|}{ Type 2 Diabetes Mellitus † } & \multicolumn{2}{|c|}{ Positive Family History of CVD † } & \multicolumn{2}{|c|}{ History of Former CVD +} & \multicolumn{2}{|c|}{ SBP* } & \multicolumn{2}{|c|}{ DBP* } & \multicolumn{2}{|c|}{ BMI* ${ }^{*}$} \\
\hline & Women & Men & Women & Men & Women & Men & Women & Men & Women & Men & Women & Men & Women & Men & Women & Men & Women & Men & Women & Men \\
\hline \multicolumn{21}{|c|}{ ARNTL } \\
\hline rs3789327 & 0.425 & 0.391 & 0.011 & 0.895 & 0.118 & 0.406 & 0.233 & 0.314 & 0.182 & 0.339 & 0.181 & 0.088 & 0.071 & 0.034 & 0.330 & 0.209 & 0.348 & 0.475 & 0.607 & 0.183 \\
\hline 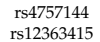 & $\begin{array}{l}0.264 \\
0.034\end{array}$ & $\begin{array}{l}0.111 \\
0.087\end{array}$ & $\begin{array}{l}0.718 \\
0.737\end{array}$ & $\begin{array}{l}0.182 \\
0.595\end{array}$ & $\begin{array}{l}0.187 \\
0.170\end{array}$ & $\begin{array}{l}0.383 \\
0.566\end{array}$ & $\begin{array}{l}0.199 \\
0.094\end{array}$ & $\begin{array}{l}0.477 \\
0.075\end{array}$ & $\begin{array}{l}0.642 \\
0.003\end{array}$ & $\begin{array}{l}0.184 \\
0.848\end{array}$ & $\begin{array}{l}0.057 \\
0.152\end{array}$ & $\begin{array}{l}0.172 \\
0.992\end{array}$ & $\begin{array}{l}0.038 \\
0.122\end{array}$ & $\begin{array}{l}0.527 \\
0.43\end{array}$ & $\begin{array}{l}0.696 \\
0.931\end{array}$ & $\begin{array}{l}0.729 \\
0.831\end{array}$ & $\begin{array}{l}0.297 \\
0.318\end{array}$ & $\begin{array}{l}0.164 \\
0.927\end{array}$ & $\begin{array}{l}0.106 \\
0.523\end{array}$ & 0.609 \\
\hline \multicolumn{21}{|c|}{ CLOCK } \\
\hline rs11932595 & 0.190 & 0.567 & 0.426 & 0.937 & 0.269 & 0.617 & 0.173 & 0.060 & 0.798 & 0.224 & 0.276 & 0.702 & 0.693 & 0.724 & 0.005 & 0.157 & 0.006 & 0.275 & 0.996 & 0.024 \\
\hline & & & & & & & & 0.431 & 0.378 & 0.693 & & 0.463 & 0.313 & 0.501 & 0.499 & 0.327 & 0.592 & 0.161 & 0.334 & 0.219 \\
\hline rs13124436 & 0.891 & 0.561 & 0.651 & 0.924 & 0.215 & 0.527 & 0.772 & 0.514 & 0.980 & 0.168 & 0.355 & 0.849 & 0.443 & 0.241 & 0.895 & 0.856 & 0.869 & 0.983 & 0.191 & 0.546 \\
\hline \multicolumn{21}{|c|}{ CRY2 } \\
\hline 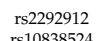 & 0.818 & 0.366 & 0.811 & 0.562 & 0.169 & 0.178 & 0.768 & $\begin{array}{l}0.020 \\
0.175\end{array}$ & 0.188 & 0.908 & $\begin{array}{l}0.840 \\
879\end{array}$ & 0.579 & 0.139 & $\begin{array}{l}0.303 \\
0.857\end{array}$ & 0.749 & $\begin{array}{l}0.503 \\
0814\end{array}$ & 0.750 & 0.515 & 0.531 & 0.834 \\
\hline \multicolumn{21}{|c|}{ PER2 } \\
\hline rs35333999 & 0.194 & 0.035 & 0.101 & 0.632 & 0.624 & 0.574 & 0.391 & 0.896 & 0.365 & 0.860 & 0.274 & 0.029 & 0.713 & 0.525 & 0.607 & 0.149 & 0.368 & 0.511 & 0.423 & 0.217 \\
\hline
\end{tabular}

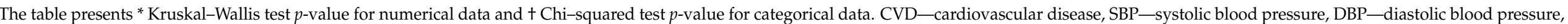
BMI—body mass index. The bold are statistically significant values. 


\section{Discussion}

The genetic variability in the ARNTL, CLOCK, CRY2 and PER2 genes in this study showed that variations in the circadian genes differ between women and men with myocardial infarction. The present study found evidence of the difference between women and men in the recessive genotype model of the rs11932595 in the CLOCK gene in the sample of 200 patients with myocardial infarction. Circadian rhythm plays a vital role in cardiac aging, which differs between men and women [9]. That is why biological sex is essential in the right approach to studying circadian rhythm in cardiovascular diseases [9].

In this study, women had a higher prevalence of dyslipidemia. Moreover, the dyslipidemia prevalence was significantly higher in women than in men. Additionally, women were significantly older than men which is similar to in the previous study [35]. Women with CVD are usually older and have more risk factors than men. Thus, both hyperlipidemia and hypertension are more common in women with MI than in men [35], which is evident in this study's results. Some of the tested circadian rhythm genes were associated with some of the CVD risk factors in women and men with MI. Thus, ARNTL rs12363415 was connected with type 2 diabetes mellitus in women, while CRY2 rs2292912 and PER2 rs 934945 were connected with dyslipidemia in men. The CLOCK rs11932595 was associated with systolic and diastolic blood pressure in women and BMI in men.

Circadian rhythm disorders in humans are associated with cardiometabolic diseases [23]. Circadian rhythm is influenced by sex, and this interaction is evident throughout most of life [23]. Women are more resistant than men to circadian rhythm disorders due to sleep disorders and shift work [23]. Circadian rhythm disorders due to shift work or sleep disorders are associated with an increased risk of cardiovascular disease, especially in men [13]. Studies in rodents have found significant sex differences in heart size and function, and sex influences cardiovascular aging [36]. Additionally, mutations in several central clock genes have been linked to many cardiovascular diseases [36].

Mutations in the CLOCK gene lead to age- and sex-dependent dilated cardiomyopathy. Aging female mice do not develop cardiomyopathy, even when the circadian rhythm is disrupted due to CLOCK gene mutation [9]. However, ARNTL (BMAL1) knock-out male mice show premature aging [9]. In mice with a CLOCK gene mutation, a circadian period is prolonged. Female mice remain healthy for a long time and do not develop cardiac dysfunction, unlike male mice that develop cardiac hypertrophy and dysfunction quickly [23]. This effect is lost after ovariectomy. In this case, the cardiometabolic function is impaired in female mice [23]. Female biological sex and estrogens lessen heart disease development and have a cardioprotective effect [13].

The lower prevalence of the rs11932595 polymorphism in women (8.1\% versus $18.4 \%$ in men) could mean two things. First, more women with the GG genotype die before surviving myocardial infarction and enrolling in the present study. Second, fewer women with the GG genotype suffered a myocardial infarction and were hospitalized. Thus, one cannot infer whether this is beneficial or detrimental. Nevertheless, patients carrying the CLOCK rs11932595 GG genotype were 2.66 times likely to have myocardial infarction.

Genetic variations in the CLOCK gene are connected with blood pressure and cardiovascular disorders in humans [37-40]. Here, an association of rs11932595, located in the CLOCK gene's intronic region, with systolic and diastolic blood pressure was found in women and with BMI in men. CLOCK knock-out and CLOCK mutant mice show an essential role of CLOCK in regulating blood pressure and kidney function [38-40]. Mice with a knock-out or mutated CLOCK gene have lower blood pressure, plasma aldosterone levels, changed urinary sodium excretion, and a higher incidence of diabetes insipidus than control mice [37-40]. A possible mechanism contributing to this is the reduced level of 20-hydroxyeicosatetraenoic acid in the CLOCK knock-out mice's urine [37,39,40]. The 20-hydroxyeicosatetraenoic acid is essential in regulating blood pressure and blood flow $[37,39,40]$. The CLOCK protein has also been associated with diabetes and obesity due to a mutation that prevents CLOCK from binding to DNA and activating target genes. Overweight women with a specific polymorphism in the $3^{\prime}$ untranslated region 
of the CLOCK gene have decreased gene expression activity, altered sleep patterns, and circadian rhythmicity [39]. Studies conducted on CLOCK mutant mice have shown the importance of CLOCK protein in daily pulse rate control, myocardial contractility, and basal metabolism [41]. Mutation of the CLOCK gene in cardiomyocytes affects only the circadian rhythm in cardiomyocytes and leads to physiological changes in cardiomyocytes. Some of these changes are cardiac metabolism, heart rate, contractility, response to external signals, cardiac growth, and regeneration [42].

In addition to CLOCK gene mutations that have been shown to affect sex-related CVD development, research has shown that mutations in the PER1 gene also affect blood pressure differently in men and women [25]. There is no dipping in blood pressure overnight in PER1 knock-out male mice [25]. Such males develop non-dipping hypertension and have an increased risk of developing CVD. PER1 knock-out female mice have a steady drop in blood pressure overnight and are protected from hypertension without dipping [25]. Sex hormones contribute to sex differences in blood pressure and cardiovascular parameters [25].

Some studies have shown that haplotypes of the ARNTL gene are associated with hypertension and type 2 diabetes $[43,44]$. In the present study, the frequency of the CGA haplotype of the ARNTL gene was $19 \%$ in women versus $11 \%$ in men, and patients carrying the mentioned haplotype were 0.45 and 0.29 times less likely to have dyslipidemia and hypertension, respectively. Kovanen et al. found the association of the CRY2 haplotype with elevated triglycerides and metabolic syndrome [45]. This study's haplotype analysis further supports this phenotype association of dyslipidemia with the CRY2 polymorphisms and haplotypes. It is observed that dyslipidemia is associated with rs2292912 CRY2 polymorphism in men, and patients carrying the CA or GA haplotypes of the CRY2 gene were 8.2 and 6.44 times likely to have dyslipidemia, respectively.

Understanding biological sex differences in cardiovascular function regulation by circadian rhythm plays an essential role in applying drug therapy or chronotherapy $[9,46]$. Biological sex is a crucial factor in the timely administration of drugs in clinical cardiology [9]. There are sex differences in the incidence, pathophysiology, and clinical presentation of heart disease. Women with ischemic heart disease have worse outcomes and are less likely to receive timely treatment than men $[47,48]$. More women, after menopause, have dyslipidemia than men [47], which is seen from the results of this study. Additionally, that contributes to the higher incidence of CVD in women after menopause. Moreover, the same diagnostic thresholds for cardiac troponin in both sexes could not be used because women with myocardial infarction have a minor cardiac troponin increase. The sex-specific diagnostic limits could improve the diagnosis of myocardial infarction in women. In women with suspected ischemic heart disease, fewer tests are performed, and often the condition remains undiagnosed. That is why women have a worse prognosis in ischemic heart disease and die more often than men [47]. All of the above might be the reason why fewer postmenopausal women are included in the study.

This study had several limitations. Sex-related differences in cardiovascular disease disappear when women reach menopause. Since the average women's age in this study was 69 years, we did not find otherwise present sex-related differences in the CVD. An additional limitation is the study sample size. A higher number of participants could yield a better association between circadian clock gene polymorphisms and myocardial infarction. Furthermore, probably, analyzed polymorphisms in the ARNTL, CRY2, and PER2 genes are not functionally associated with myocardial infarction. In this case, functional SNPs or a set of functionally relevant polymorphisms that could be strongly associated with myocardial infarction should be named. This approach to the problem of myocardial infarction provides an opportunity to continue research in multicenter studies with many participants. This research's advantage is that the participants involved were homogeneous in demographic background characteristics such as ethnicity. 


\section{Conclusions}

This study showed that genetic variation of the CLOCK gene was a biological sex difference in myocardial infarction patients. Premenopausal women have a lower prevalence of cardiovascular disease than men of the same age due to estrogen's protective effect. However, after menopause, the prevalence of diseases like coronary heart disease and heart failure increases dramatically and exceeds the prevalence in men of the same age. In this study, postmenopausal women were older than men. This age difference might contribute to a higher incidence of CVD in women with worse outcomes, which is a possible reason why no more significant differences were observed between men and women in the present study. The application of circadian biology in clinical practice represents a significant possibility of reducing patients' morbidity or mortality after myocardial infarction. For both sexes to benefit from CVD treatment, biological sex should be considered for chronotherapy. Additional research and analysis of the sex-related circadian clock are possible.

Supplementary Materials: The following are available online at https:/ /www.mdpi.com/article/10 $.3390 /$ jcdd 8050053 / s1, Table S1: Frequencies and distribution of probable haplotypes in the women and the men.

Author Contributions: I.Š., J.T., and M.J. were responsible for formal analysis, investigation, and methodology. I.Š. was responsible for the visualization. R.S. was responsible for validation and supervision the study. I.Š. wrote the manuscript. I.Š., J.T., M.J., and R.S. reviewed and edited the manuscript. All authors have read and agreed to the published version of the manuscript.

Funding: This research was funded by a grant from the Croatian Ministry of Science and Education and dedicated to multi-year institutional financing of scientific activity at the Josip Juraj Strossmayer University of Osijek, Osijek, Croatia, grant number IP8-FDMZ-2020.

Institutional Review Board Statement: The study was conducted according to the Declaration of Helsinki's guidelines and approved by the Ethics Committee of the University Hospital Osijek (Ethical Approval Code: 25-1:3160-3/2012).

Informed Consent Statement: Informed consent was obtained from all patients involved in the study.

Data Availability Statement: The dataset generated during the study is available from the corresponding author on reasonable request.

Conflicts of Interest: The authors declare no conflict of interest. The funders had no role in the design of the study, in the collection, analyses, or interpretation of data, in the writing of the manuscript, or in the decision to publish the results.

\section{References}

1. Hower, I.M.; Harper, S.A.; Buford, T.W. Circadian rhythms, exercise, and cardiovascular health. J. Circadian Rhythm. $2018,16,7$. [CrossRef] [PubMed]

2. Škrlec, I.; Milić, J.; Heffer, M.; Wagner, J.; Peterlin, B. Circadian clock genes and circadian phenotypes in patients with myocardial infarction. Adv. Med. Sci. 2019, 64, 224-229. [CrossRef]

3. Crnko, S.; Du Pré, B.C.; Sluijter, J.P.G.; Van Laake, L.W. Circadian rhythms and the molecular clock in cardiovascular biology and disease. Nat. Rev. Cardiol. 2019, 16, 437-447. [CrossRef] [PubMed]

4. Škrlec, I.; Marić, S.; Včev, A. Myocardial infarction and circadian rhythm. In Visions of Cardiomyocyte-Fundamental Concepts of Heart Life and Disease; IntechOpen: London, UK, 2019; pp. 21-35.

5. Jain, M.; Zhang, L.; Sabeh, M. Circadian rhythm and cardiovascular disorders. Chrono. Ther. 2014, 4, 27. [CrossRef]

6. Š Škrlec, I.; Milić, J.; Cilenšek, I.; Petrovič, D.; Wagner, J.; Peterlin, B. Circadian clock genes and myocardial infarction in patients with type 2 diabetes mellitus. Gene 2019, 701, 98-103. [CrossRef] [PubMed]

7. Duffy, J.F.; Cain, S.W.; Chang, A.-M.; Phillips, A.J.K.; Münch, M.Y.; Gronfier, C.; Wyatt, J.K.; Dijk, D.-J.; Wright, K.P.; Czeisler, C.A. Sex difference in the near-24-hour intrinsic period of the human circadian timing system. Proc. Natl. Acad. Sci. USA 2011, 108, 15602-15608. [CrossRef] [PubMed]

8. Boivin, D.B.; Shechter, A.; Boudreau, P.; Begum, E.A.; Ying-Kin, N.M.K.N. Diurnal and circadian variation of sleep and alertness in men vs. naturally cycling women. Proc. Natl. Acad. Sci. USA 2016, 113, 10980-10985. [CrossRef] [PubMed]

9. Pyle, W.G.; Martino, T.A. Circadian rhythms influence cardiovascular disease differently in males and females: Role of sex and gender. Curr. Opin. Physiol. 2018, 5, 30-37. [CrossRef] 
10. Thosar, S.S.; Butler, M.P.; Shea, S.A. Role of the circadian system in cardiovascular disease. J. Clin. Investig. 2018, $128,2157-2167$. [CrossRef]

11. Budkowska, M.; Lebiecka, A.; Marcinowska, Z.; Woźniak, J.; Jastrzębska, M.; Dołęgowska, B. The circadian rhythm of selected parameters of the hemostasis system in healthy people. Thromb. Res. 2019, 182, 79-88. [CrossRef] [PubMed]

12. Škrlec, I.; Milić, J.; Steiner, R. The impact of the circadian genes clock and arntl on myocardial infarction. J. Clin. Med. 2020, 9, 484. [CrossRef]

13. Alibhai, F.J.; Reitz, C.J.; Peppler, W.T.; Basu, P.; Sheppard, P.; Choleris, E.; Bakovic, M.; Martino, T.A. Female Clock $\Delta 19 / \Delta 19$ mice are protected from the development of age-dependent cardiomyopathy. Cardiovasc. Res. 2018, 114, 259-271. [CrossRef] [PubMed]

14. Škrlec, I.; Milic, J.; Heffer, M.; Peterlin, B.; Wagner, J. Genetic variations in circadian rhythm genes and susceptibility for myocardial infarction. Genet. Mol. Biol. 2018, 41, 403-409. [CrossRef] [PubMed]

15. Silva-Urra, J.A.; Núñez-Espinosa, C.A.; Niño-Mendez, O.A.; Gaitán-Peñas, H.; Altavilla, C.; Toro-Salinas, A.; Torrella, J.R.; Pagès, T.; Javierre, C.F.; Behn, C.; et al. Circadian and sex differences after acute high-altitude exposure: Are early acclimation responses improved by blue light. Wilderness Environ. Med. 2015, 26, 459-471. [CrossRef]

16. Zhao, R.; Li, D.; Zuo, P.; Bai, R.; Zhou, Q.; Fan, J.; Li, C.; Wang, L.; Yang, X. Influences of age, gender, and circadian rhythm on deceleration capacity in subjects without evident heart diseases. Ann. Noninvasive Electrocardiol. 2014, 20, 158-166. [CrossRef]

17. Eastman, C.I.; Tomaka, V.A.; Crowley, S.J. Sex and ancestry determine the free-running circadian period. J. Sleep Res. 2017, 26, 547-550. [CrossRef]

18. Link, J.C.; Reue, K. Genetic basis for sex differences in obesity and lipid metabolism. Annu. Rev. Nutr. 2017, 37, 225-245. [CrossRef] [PubMed]

19. Qian, J.; Morris, C.J.; Caputo, R.; Wang, W.; Garaulet, M.; Scheer, F.A.J.L. Sex differences in the circadian misalignment effects on energy regulation. Proc. Natl. Acad. Sci. USA 2019, 116, 23806-23812. [CrossRef]

20. Arnold, A.P.; Cassis, L.A.; Eghbali, M.; Reue, K.; Sandberg, K. Sex hormones and sex chromosomes cause sex differences in the development of cardiovascular diseases. Arter. Thromb. Vasc. Biol. 2017, 37, 746-756. [CrossRef] [PubMed]

21. Čulić, V.; Eterović, D.; Mirić, D.; Rumboldt, Z.; Hozo, I. Gender differences in triggering of acute myocardial infarction. Am. J. Cardiol. 2000, 85, 753-756. [CrossRef]

22. Hatcher, K.M.; Royston, S.E.; Mahoney, M.M. Modulation of circadian rhythms through estrogen receptor signaling. Eur. J. Neurosci. 2020, 51, 217-228. [CrossRef]

23. Anderson, S.T.; Fitzgerald, G.A. Sexual dimorphism in body clocks. Science 2020, 369, 1164-1165. [CrossRef] [PubMed]

24. Škrlec, I.; Milić, J.; Heffer, M.; Steiner, R.; Peterlin, B.; Wagner, J. Association of circadian rhythm with myocardial infarction. Acta Clin. Croat. 2018, 57, 480-486. [CrossRef] [PubMed]

25. Douma, L.G.; Solocinski, K.; Holzworth, M.R.; Crislip, G.R.; Masten, S.H.; Miller, A.H.; Cheng, K.-Y.; Lynch, I.J.; Cain, B.D.; Wingo, C.S.; et al. Female C57BL/6J mice lacking the circadian clock protein PER1 are protected from nondipping hypertension. Am. J. Physiol. Integr. Comp. Physiol. 2019, 316, R50-R58. [CrossRef] [PubMed]

26. Touitou, Y.; Bogdan, A. Circadian and seasonal variations of physiological and biochemical determinants of acute myocardial infarction. Biol. Rhythm. Res. 2007, 38, 169-179. [CrossRef]

27. Campbell, D.J. Why do men and women differ in their risk of myocardial infarction. Eur. Heart J. 2008, 29, 835-836. [CrossRef] [PubMed]

28. Breet, N.J.; Sluman, M.A.; Van Berkel, M.A.J.P.J.; Van Werkum, J.W.; Bouman, H.J.; Harmsze, A.M.; Kelder, J.C.; Zijlstra, F.; Hackeng, C.M.; Berg, J.M.T. Effect of gender difference on platelet reactivity. Neth. Hear. J. 2011, 19, 451-457. [CrossRef]

29. Thygesen, K.; Alpert, J.S.; Jaffe, A.S.; Simoons, M.L.; Chaitman, B.R.; White, H.D. Third universal definition of myocardial infarction. Nat. Rev. Cardiol. 2012, 9, 620-633. [CrossRef]

30. Thygesen, K.; Alpert, J.S.; Jaffe, A.S.; Chaitman, B.R.; Bax, J.J.; Morrow, D.A.; White, H.D. ESC scientific document group fourth universal definition of myocardial infarction. Eur. Heart J. 2019, 40, 237-269. [CrossRef]

31. Garaulet, M.; Madrid, J.A. Chronobiology, genetics and metabolic syndrome. Curr. Opin. Lipidol. 2009, 20, 127-134. [CrossRef]

32. Leu, H.-B.; Chung, C.-M.; Lin, S.-J.; Chiang, K.-M.; Yang, H.-C.; Ho, H.-Y.; Ting, C.-T.; Lin, T.-H.; Sheu, S.-H.; Tsai, W.-C.; et al. Association of circadian genes with diurnal blood pressure changes and non-dipper essential hypertension: A genetic association with young-onset hypertension. Hypertens. Res. 2015, 38, 155-162. [CrossRef]

33. Englund, A.; Kovanen, L.; Saarikoski, S.T.; Haukka, J.; Reunanen, A.; Aromaa, A.; Lönnqvist, J.; Partonen, T. NPAS2 and PER2 are linked to risk factors of the metabolic syndrome. J. Circadian Rhythm. 2009, 7, 5. [CrossRef]

34. Solé, X.; Guinó, E.; Valls, J.; Iniesta, R.; Moreno, V. SNPStats: A web tool for the analysis of association studies. Bioinformatics 2006, 22, 1928-1929. [CrossRef] [PubMed]

35. Moshki, M.; Zareie, M.; Hashemizadeh, H. Sex differences in acute myocardial infarction. Nurs. Midwifery Stud. 2015, 4, 22395. [CrossRef] [PubMed]

36. Forman, D.E.; Cittadini, A.; Azhar, G.; Douglas, P.S.; Wei, J.Y. Cardiac morphology and function in senescent rats: Gender-related differences. J. Am. Coll. Cardiol. 1997, 30, 1872-1877. [CrossRef]

37. Rhoads, M.K.; Balagee, V.; Thomas, S.J. Circadian regulation of blood pressure: Of mice and men. Curr. Hypertens. Rep. 2020, 22, 1-9. [CrossRef]

38. Douma, L.G.; Gumz, M.L. Circadian clock-mediated regulation of blood pressure. Free. Radic. Biol. Med. 2018, 119, 108-114. [CrossRef] [PubMed] 
39. Richards, J.; Diaz, A.N.; Gumz, M.L. Clock genes in hypertension. Blood Press. Monit. 2014, 19, 249-254. [CrossRef]

40. Mikulska, A.; Grzelak, T.; Pelczyńska, M.; Bogdański, P.; Czyżewska, K. Assessment of selected clock proteins (clock and cry1) and their relationship with biochemical, anthropometric, and lifestyle parameters in hypertensive patients. Biomolecules 2021, 11, 517. [CrossRef]

41. Scott, E.M. Circadian clocks, obesity and cardiometabolic function. Diabetes Obes. Metab. 2015, 17, 84-89. [CrossRef]

42. Bray, M.S.; Shaw, C.A.; Moore, M.W.S.; Garcia, R.A.P.; Zanquetta, M.M.; Durgan, D.J.; Jeong, W.J.; Tsai, J.-Y.; Bugger, H.; Zhang, D.; et al. Disruption of the circadian clock within the cardiomyocyte influences myocardial contractile function, metabolism, and gene expression. Am. J. Physiol. Circ. Physiol. 2008, 294, H1036-H1047. [CrossRef] [PubMed]

43. Dibner, C.; Schibler, U. Circadian timing of metabolism in animal models and humans. J. Intern. Med. 2015, $277,513-527$. [CrossRef] [PubMed]

44. Sookoian, S.; Gemma, C.; Gianotti, T.F.; Burgueño, A.; Castaño, G.; Pirola, C.J. Genetic variants of clock transcription factor are associated with individual susceptibility to obesity. Am. J. Clin. Nutr. 2008, 87, 1606-1615. [CrossRef] [PubMed]

45. Kovanen, L.; Donner, K.; Kaunisto, M.; Partonen, T. CRY1, CRY2 and PRKCDBP genetic variants in metabolic syndrome. Hypertens. Res. 2014, 38, 186-192. [CrossRef]

46. Škrlec, I. Circadian rhythm and myocardial infarction. Med. Flum. 2019, 55, 32-42. [CrossRef]

47. Calabrò, P.; Niccoli, G.; Gragnano, F.; Grove, E.L.; Vergallo, R.; Mikhailidis, D.P.; Patti, G.; Spaccarotella, C.; Katsiki, N.; Masiero, G.; et al. Are we ready for a gender-specific approach in interventional cardiology. Int. J. Cardiol. 2019, 286, 226-233. [CrossRef] [PubMed]

48. Gul, B.; Kozuma, K.; Haimi, I.; Zhao, W.; Simonton, C.; Ying, S.-W.; Buda, A.; Mehta, S.; Baumbach, A.; Lansky, A. Sex disparities in acute myocardial infarction care and outcomes. Catheter. Cardiovasc. Interv. 2018, 92, E341-E347. [CrossRef] [PubMed] 